\title{
OPEN RETROPUBIC AND ROBOT-ASSISTED RADICAL PROSTATECTOMY IN PROSTATE CARCINOMA: ADVANTAGES OF METHODS
}

\author{
Nikolay H. Kolev, \\ Jitian A. Atanasov, \\ Vladislav R. Dunev, \\ Boyan A. Stoykov, \\ Rumen P. Kotsev, \\ Alexander Vanov, \\ Fahd Al-Shargabi, \\ Pencho T. Tonchev', \\ Sergey D. Iliev', \\ Toni I. Stoyanov ${ }^{2}$
}

Department of Urology, Medical University - Pleven, Bulgaria

${ }^{1}$ Department of Surgery, Medical University - Pleven, Bulgaria

${ }^{2}$ Department of General Surgery, General Hospital of Villarobledo, Spain

\author{
Corresponding Author: \\ Nikolay H. Kolev \\ Clinic of Urology, \\ University Hospital - Pleven \\ 8a, G. Kochev Blvd. \\ Pleven, 5800 \\ Bulgaria \\ e-mail:kolevmd@yahoo.com
}

Received: December 16, 2016

Revision received: December 19, 2016

Accepted: December 20, 2016

\begin{abstract}
Summary
Prostate cancer (PC) is the most common type of cancer in men in a number of countries. The choice of surgical technique for radical prostatectomy (RP) concerns both patients and urologists. The choice is not easy to make, since data is still limited due to the lack of large multicentric randomized research trials. For three years (2011-2014), 244 patients with limited prostate cancer were operated in the Urology Clinic of the University Hospital in Pleven. Robot-assisted radical prostatectomy (RARP) was performed on 35 patients (14\%), open retropubic radical prostatectomy (ORP) - on 199 patients (81\%), and laparoscopic RP - on 12 patients $(5 \%)$. The preoperative and post-op results from the first two groups were compared. For the follow-up period of 12 months, functional results in 82 patients of the ORP group were compared to the results in the 35 patients of the RARP group. The operative time was significantly longer in the RARP group, and blood loss was lower. The catheter stay was shorter in patients with RARP. The percentage of significant postoperative complications was $0 \%$ in the patients with RARP and 3\% in the patients with an ORP. RARP patients demonstrated better continence: $91 \%$ vs. $87 \%$ and erectile function $46 \%$ vs. $40 \%$ at 12 months.
\end{abstract}

Key words: robot-assisted radical prostatectomy, open radical prostatectomy, functional results

\section{Introduction}

In recent years, prostate cancer $(\mathrm{PC})$ has had the highest incidence of cancers in men, as many of the current studies have shown [1].Today the surgical treatment performed in the early stages of the disease remains the most efficient method for a permanent cure [2]. There were 20897 registered patients with $\mathrm{PC}$ in Bulgaria for 2009. Improvement in diagnostic methods during the last few years resulted in an increased detection: 2783 new cases were registered in 2015. The number of patients treated surgically in Bulgaria has also increased. PC is diagnosed relatively late, in the advanced stages in Bulgaria as compared to Europe and the United States, thus reducing the survival rate of the patients (Table 1).

Radical prostatectomy (RP) includes removal of the prostate gland along with the seminal vesicles, with an option for extirpation of the regional lymph nodes.

Retropubic radical prostatectomy is a well- 
established operative technique verified through a number of randomized clinical trials and evident functional and oncological results. Other operative methods for RP are laparoscopic and robot-assisted techniques. Robot-assisted radical prostatectomy (RARP) is the most modern operative approach in cases of PC. The robotic hands allow finer movements almost impossible for the human hand. The combination with a three-dimensional, extremely detailed visualization of the operative field makes it possible to achieve precise control over the neuro-vascular structures near the prostate gland. This reduces the most common complications after RP - incontinence and erectile dysfunction.

The purpose of this study was to compare preoperative data and postoperative results in patients operated with open, retropubic(ORP) and RARP, consider early and late complications, and analyze the data for their functional results (continence and erectile function) during the 12month follow-up.

Table 1. Morbidity, mortality, and five-year survival rate of PC in Bulgaria, Europe and the United States

\begin{tabular}{llll}
\hline & Bulgaria & Europe & US A \\
\hline Morbidity* & 37 & 96 & 138 \\
\hline Mortality* & 17 & 19 & 21 \\
\hline 5 - year survival rate & $54 \%$ & $84 \%$ & $99 \%$ \\
\hline
\end{tabular}

*of 100000 men

\section{Materials and Methods}

We operated on 244 patients with limited prostate cancer for three years (2011-2014) in the Urology Clinic of University Hospital - Pleven. RARP was performed on 35 patients (14\%), 199 patients $(81 \%)$ were operated with ORP, and 12 patients
(5\%) - with laparoscopic RP (Figure 1). The preoperative data and post-op results from the first two groups were compared. For the followup period of 12 months, functional results (continence and erectile function) were assessed in 82 patients with ORP and in 35 patients with RARP.

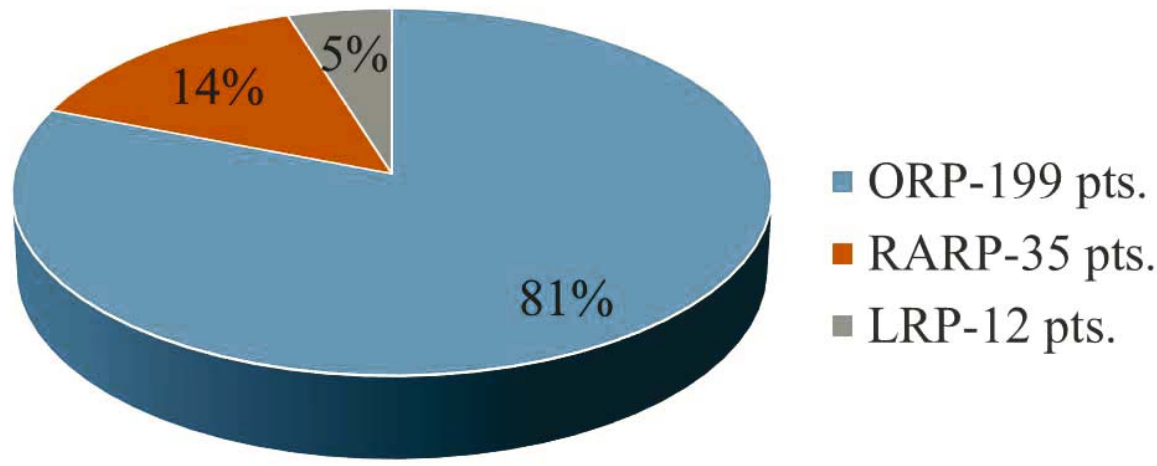

Figure 1. The distribution of patients according to operational methods applied

\section{Results}

Data about the age of patients, stage of the PC, prostate specific antigen (PSA) level, Gleason score and prostate volume are presented on Table 2.

PC patients were treated as follows: $82.2 \%$
RARP (Group 2) and 5.5\% underwent laparoscopic surgery.

The average age of the patients in the RARP group was 61years, and 65 years - in the ORP group. A significant difference of cT stage value and volume of the prostate gland between the two groups was found. There were no significant differences in preoperative Gleason score and 
Table 2. Pre-operative and postoperative data of patients with ORP and RARP

\begin{tabular}{|c|c|c|c|c|}
\hline z Variable & Comparison & RARP & ORP & p-value \\
\hline Age & Median (range) & $61(50-71)$ & $65(49-73)$ & - \\
\hline \multirow{3}{*}{ Clinical stage (cT) } & $\operatorname{cT} 1(\%)$ & $14(40 \%)$ & $45(23 \%)$ & \multirow{3}{*}{$\mathrm{p}<0.005$} \\
\hline & cT2 (\%) & $21(60 \%)$ & $130(65 \%)$ & \\
\hline & cT3 (\%) & $0(0 \%)$ & $24(12 \%)$ & \\
\hline Volume & Median (range) & $42(30-60)$ & $51(20-85)$ & $\mathrm{p}<0.005$ \\
\hline PSA preoperative & Median (range) & $9.7(4-18)$ & $10.6(2.5-12.3)$ & - \\
\hline $\begin{array}{l}\text { Gleason Score - } \\
\text { preoperative }\end{array}$ & Median (range) & $7(6-7)$ & $7(6-7)$ & - \\
\hline \multirow{3}{*}{$\begin{array}{l}\text { Final pathological stage } \\
(\mathrm{pT})\end{array}$} & pT2 (\%) & $20(58 \%)$ & $117(59 \%)$ & - \\
\hline & pT3 (\%) & $15(42 \%)$ & $82(41 \%)$ & - \\
\hline & pT4 (\%) & $0(0 \%)$ & $0(0 \%)$ & - \\
\hline $\begin{array}{l}\text { Gleason Score - } \\
\text { postoperative }\end{array}$ & Median (range) & $7(6-8)$ & $7(6-7)$ & - \\
\hline
\end{tabular}

The operating time was significantly longer in the RARP group (290 min vs. $130 \mathrm{~min}$ ). Blood loss was significantly lower in patients of the RARP (330 $\mathrm{ml}$ against $460 \mathrm{ml}$ ). The catheter stay was shorter in patients with RARP. Percentage of significant postoperative complications (Clavien-Dindo III-IV) was $0 \%$ in the patients with RARP and $3 \%$ in patients with an ORP.
RARP patients demonstrated better continence: $91 \%$ vs. $87 \%$ and erectile function $46 \%$ vs. $40 \%$ at 12 months. Percentages of nerve-sparing interventions in the two groups were similar (Table 3).

Patients with RARP had significantly better functional results (Table 4).

Table 3. Operation indicators

\begin{tabular}{lllll}
\hline Variable & Comparison & RARP & ORP & p-value \\
\hline Surgical time (min) & Median (range) & $290(165-410)$ & $130(110-230)$ & $\mathrm{p}<0.005$ \\
\hline \multirow{2}{*}{ Nerve-sparing } & Bilateral & $15(42 \%)$ & $81(40 \%)$ & \\
\hline Blood loss (ml) & Mnilateral & $11(31 \%)$ & $52(26 \%)$ & \\
\hline Catheter (days) & Median (range) & $330(50-2000)$ & $460(500-1500)$ & $\mathrm{p}<0.005$ \\
\hline $\begin{array}{l}\text { Overall } \\
\text { complication rate } \\
(\%)\end{array}$ & Clavien-Dindo I-II & 13 & $9(8-17)$ & $\mathrm{p}<0.005$ \\
\cline { 2 - 5 } & Clavien-Dindo III-IV & 0 & 16 & $\mathrm{p}<0.005$ \\
\hline
\end{tabular}

Table 4. Functional results

\begin{tabular}{llll}
\hline Variable (questionnaires) & RARP - patients (\%) & $\begin{array}{l}\text { ORP - patients (\%) } \\
\text { (follow up of 82 } \\
\text { patients) }\end{array}$ & p-value \\
\hline $\begin{array}{l}\text { Continence(0-1pad/day): } \\
\begin{array}{l}\text { after 6 months } \\
\text { after 12 months }\end{array}\end{array}$ & $31(89 \%)$ & $66(81 \%)$ & $\mathrm{p}<0.005$ \\
\hline $\begin{array}{l}\text { Restored erectile function } \\
\text { after 12 months }\end{array}$ & $32(91 \%)$ & $71(87 \%)$ & $\mathrm{p}<0.005$ \\
\hline
\end{tabular}




\section{Discussion}

There is a long-term trend of increasing morbidity and mortality from $\mathrm{PC}$.

Albertsen et al. have reported $152 \mathrm{~min}$ operating time and average blood loss of $166 \mathrm{ml}$, and need for blood transfusion in $0.2 \%$ of cases [2]. The average postoperative hospital stay reported was 1.9 days, and the catheter was removed after 6.3 days. According to our data, the average operating time in the group with RARP was $290 \mathrm{~min}$, compared to $130 \mathrm{~min}$ in the ORP group. This significant difference could be attributed to gaining start-up experience (learning curve) in robotic surgery. The average blood loss, the catheter and hospital stay, and major complications were lower in the group with RARP.

According to a randomized clinical trial of Montorsi et al. [3], the level of positive surgical margins (PSM) was $20 \%$ in ORP and $16 \%$ in RARP. Smith et al. had similar results [4]. The percentage of PSM was significantly lower in the RARP group. The data from our study showed that PSM in RARP was $23 \%$ and $25 \%$ in ORP group.

According to a series of publications of Ficarra et al. [5-7], there was a significant difference regarding potency, early and late continence in benefit of patients operated with RARP, as compared to ORP. Our data confirmed those results. Continence after 12 months in patients with RARP was $91 \%$, as compared to $87 \%$ of those with open surgery.

Robotic radical prostatectomy has a number of advantages in surgical treatment of PC. RARP can be applied routinely with little risk of complications. Results also depend on the experience of surgeons, patient clinical data and characteristics of carcinomas.

\section{Conclusions}

Based on the intra- and postoperative, and functional results we achieved, it can be concluded that in patients with RARP there were lower blood loss, fewer severe postoperative complications, shorter catheterization and hospital stay. However, the operative time in patients with ORP was shorter than in RARP. On the other hand, continence and erectile function in patients operated on with robot-assisted operations were significantly better.

There are two centers for robotic surgery in our country. The first one was opened in the Medical University of Pleven, where we carried out the first RARP in Bulgaria (2010, DaVinci S System). In 2014, a second robotic system Da Vinci Si was installed in Pleven. Another centre for robotic surgery was opened in Doverie Hospital in Sofia in 2013. Robotic-assisted radical prostatectomy should be reimbursed by the National health insurance fund. This would provide wider access to the benefits this method offers to patients with PC.

\section{References}

1. Zhou CK, Check DP, Lortet-Tieulent J, Laversanne M, Jemal A, Ferlay J, et al. Prostate cancer incidence in 43 populations worldwide: An analysis of time trends overall and by age group. Int J Cancer. 2016;138(6):1388-400.

2. Albertsen PC. Robot-assisted radical prostatectomy - fake innovation or the real deal? Eur Urol. 2012;62(3):365-7.

3. Montorsi F, Wilson TG, Rosen RC, Ahlering TE, Artibani W, Carroll PR, et al. Best practices in robot-assisted radical prostatectomy: Recommendations of the Pasadena consensus panel. Eur Urol. 2012;62(3):368-81.

4. Smith JA, Herrell SD. Robotic-assisted laparoscopic prostatectomy: do minimally invasive approaches offer significant advantages? J Clin Oncol. 2005;23(32):8170-5.

5. Ficarra V, Novara G, Artibani W, Cestari A, Galfano A, Graefen M, et al. Retropubic, laparoscopic, and robot-assisted radical prostatectomy: a systematic review and cumulative analysis of comparative studies. Eur Urol. 2009;55(5):1037-63.

6. Ficarra V, Novara G, Fracalanza S, D'Elia C, Secco $\mathrm{S}$, Iafrate $\mathrm{M}$, et al. A prospective, non-randomized trial comparing robot-assisted laparoscopic and retropubic radical prostatectomy in one European institution. BJU Int. 2009;104(4):534-9.

7. Novara G, Ficarra V, Rosen RC, Artibani W, Costello A, Eastham JA, et al. Systematic review and meta-analysis of perioperative outcomes and complications after robot-assisted radical prostatectomy. Eur Urol. 2012;62(3):431-52. 